\title{
The main directions of development of the international legal mechanism for regulating environmental migration
}

\author{
Yury Shpakovsky ${ }^{1, *}$ and Vladimir Yevtushenko $^{2}$ \\ 'Doctor of Legal Sciences, Professor, State Law University, 101000 Moscow, Russia \\ ${ }^{2}$ Candidate of Legal Sciences, National Research University, 308600 Belgorod, Russia
}

\begin{abstract}
The article analyzes directions of development of the international legal mechanism for regulating environmental migration. Two directions were described. The first one involves the extension of the 1951 UN Convention on the Legal Status of Refugees to environmental migrants who have left their permanent places of residence due to an environmental degradation caused by natural or man-made disasters or negative impacts of industrial and economic activities. The second way to create an international legal mechanism for regulating environmental migration and protecting environmental migrants is to develop and adopt a new international agreement governing actions of the international community aimed to protect environmental migrants. The analysis allows for the conclusion that the first direction seems to be the most optimal due to the similar status of asylum seekers and people who have left their places of permanent residence as a result of natural disasters or industrial accidents, environmental and climatic conditions.
\end{abstract}

\section{Introduction}

Migration of the population from places of their permanent residence due to natural and natural disasters, industrial accidents, human economic and environmental activities, changes in climatic conditions cause by global warming is gaining more and more recognition both at the international and national levels. The issue is relevant for the countries and regions where this problem is acute due to various natural, technogenic or climatic factors [1]. Issues of development of the legal mechanism are still being discussed despite the fact that the concept "environmental migrant" was proposed by American ecologist William Vogt in 1948 [2]. As applied to persons who left their place of residence due to environmental factors, the concept "environmental refugee" was proposed by Lester Brown in 1976 [3].

The need to create an international legal mechanism for regulating environmental migration - forced displacement of people for environmental reasons - has been discussed at various international meetings devoted to the problems of forced migration and environmental and climate problems.

This issue was discussed the regional conference on the problems of regulation of forced migration in 1996 in Geneva, Switzerland. In addition to the adoption of the document emphasizing the need to create an international legal mechanism to regulate forced migration due to environmental degradation (environmental migration) and protection of the rights and freedoms of environmental migrants, the definition of the concept "Environmental migrant" was formulated.
According to the definition, environmental migrants are "... people who are forced to leave their place of permanent residence and who move within their country beyond its border due to a sharp deterioration in the environment or environmental disasters."

\section{Materials and methods}

Monitoring of decisions adopted at various international conferences, documents of various international and regional organizations, scientific publications in the field of sociology and law, the authors counted nearly two dozen definitions of the concepts "environmental migration" and "environmental migrant".

The definitions of the concept "environmental migration" slightly differs from that adopted at the regional conference in Geneva. As a rule, environmental migration is defined as forced migration of the population both within the country and abroad due to environmental disasters or environmental degradation causing negative impacts on the life and health of local residents. The rapidity of changes in the environmental situation varies from sharp to gradual changes in the environment, depending on whether environmental migration, is considered only as a result of an escape from a sharp change in the environmental situation as a result of natural disasters and industrial accidents and their consequences, or population migration from areas with severe environmental conditions, deteriorating as a result of intensive industrial and national economic activities.

\footnotetext{
"Corresponding author: 77712@live.ru
} 
This view of ecological migration was formulated at the first international conference on environment-related migration held in Bonn (Germany) in 2008. The conference was devoted to the problems of development of a mechanism for international legal regulation of environmental migration. Environmental issues, forced migration of the population from the areas of their permanent residence were at the agenda of this international scientific and public forum.

Categories of environmental migrants were identified, including "emergency environmental migrants" - people who left the place of their permanent or temporary residence due to a sharp deterioration in the environmental situation caused by natural disasters or technological accidents and their consequences.

The next category of environmental migrants is "forced environmental migrants". They are people who migrate to ecologically safe areas due to the difficult environmental situation prevailing at the place of their former residence, environmental degradation, etc. caused by intensive industrial and environmental activities.

One more category of the environmental migration is "voluntary environmental migrants" - persons who have means and abilities to leave ecologically disadvantaged areas on their own. This category of environmental migrants needs help and protection as well.

The conference dealt with the need to create a mechanism for international legal regulation of migration caused by dramatic climate changes in some areas as a result of the global warming (the "climate migration").

This position was confirmed at the Nansen Conference on Climate Changes and Population Movement in the 21st Century held in 2011 in Oslo, Norway. It was dedicated to the 150th anniversary of the birth of Fridtjof Nansen, a famous Norwegian polar explorer, and his international activities aimed to protect forced migrants. At the conference, 10 Nansen Principles were adopted. They are the basis for the actions of the international community and governments aimed to prevent and regulate the movement of forced migrants in the event of sharp climatic changes and other natural disasters.

\section{Results}

The need for the international legal regulation of environmental migration has been declared by various international organizations, whose tasks include protection of rights of various categories of migrants. The need for this step was declared by the Global Commission on International Migration of the United Nations, and the International Organization for Migration (IOM).

Despite the fact that environmental migration is interpreted as forced migration, a single way to create an international legal mechanism for regulating this type of migration has not yet been developed. Currently, several directions of its formation have been proposed.

\section{Discussion}

The first direction involves expanding the scope of the main international multilateral agreement on the regulation of forced migration - the $1951 \mathrm{UN}$ Convention on the Legal Status of Refugees and its 1967 protocol. This direction provides that the UN Convention will protect both refugees - "... persons who have left the state of their nationality or permanent residence due to persecution based on race, religion, citizenship, membership in a particular social group or political opinion ..." , and environmental migrants - people who left the place of their permanent residence due to environmental degradation as a result of natural or manmade disasters, negative impacts of industrial and economic activities on the environment, or climatic changes (an increase in the level of temperatures due to the global warming and other natural and climatic phenomena) and related negative effects. 


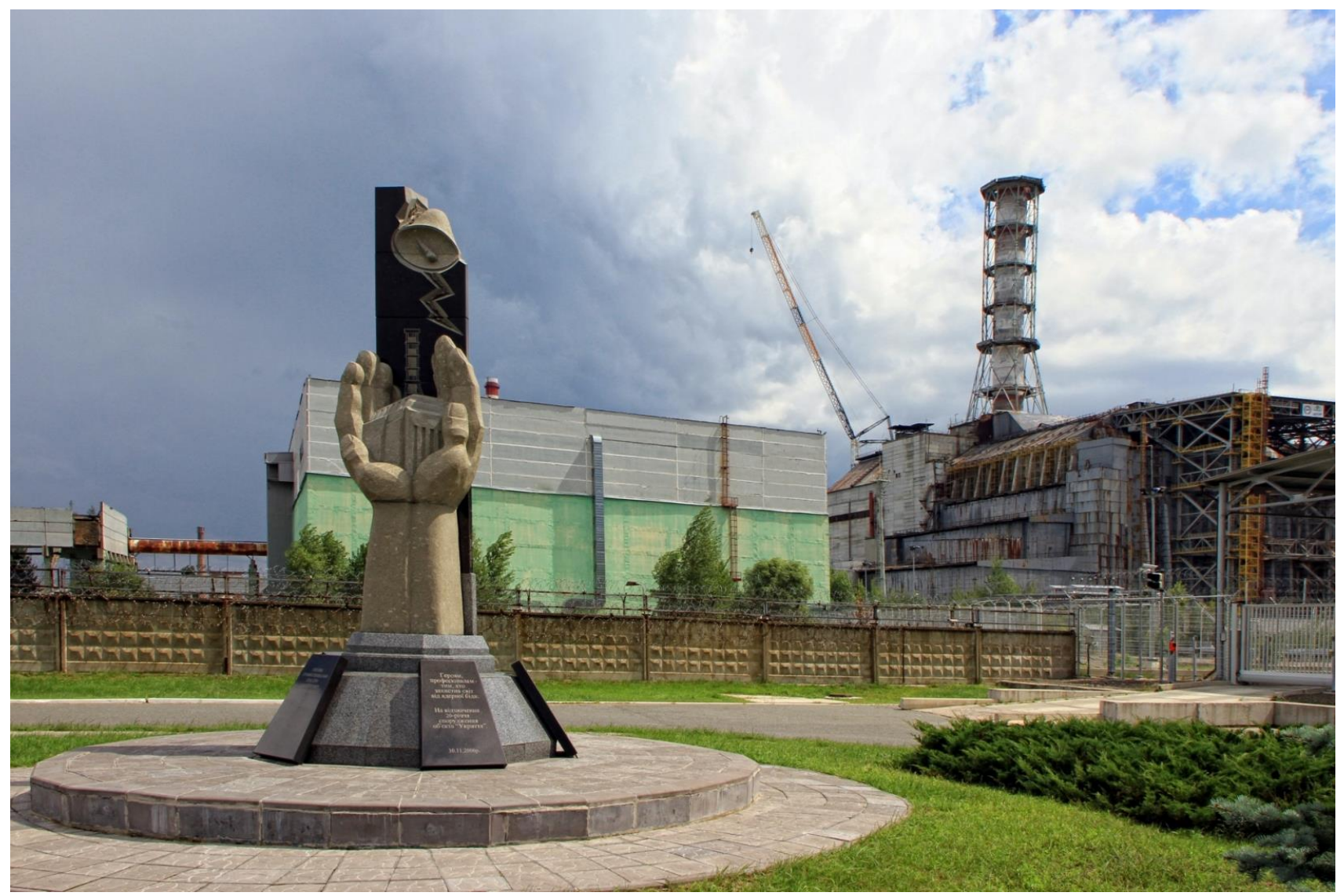

Fig. 1. Monument to Chernobyl accident

It should be noted that this option is opposed by the UN head agency working with refugees - the Office of the UN High Commissioner for Refugees (UNHCR) which believes that the extension of the $1951 \mathrm{UN}$ Convention on the Legal Status of Refugees and its 1967 protocol to another category of forced migrants requiring protection and assistance will adversely affect activities of the UNHCR and its specialized aimed to protect classical refugees - victims of "... persecution based on race, religion, citizenship, membership of a particular social group or political opinion ...". In addition, the UNHCR has a negative attitude towards the equalization of these two reasons for forced migration - persecution based on race, religion, citizenship, etc. and a threat to human life and health due to environmental degradation as a result of natural and man-made disasters or negative impacts of industrial and economic activities or climate changes [4].

The second way to create an international legal mechanism for regulating environmental migration and solving the problem of protecting environmental migrants is to develop and adopt a new international agreement governing actions of the international community to protect rights of environmental migrants. This solution involves creating a new office or agency within the UN structure that will play a coordinating role in the system of interaction of the international community with environmental and climate migrants. In carrying out this activity, the new UN structural entity should interact with other departments both within the
UN system and independent international organizations - the UNHCR and IOM; with the UN Children's Fund and the Red Cross due to the fact that these activities largely overlap with objectives of these international organizations.

In implementing these measures, other international organizations may be involved. Accordingly, the governments of the countries of origin of environmental and climate migrants and host countries should interact with environmental migrants.

At the first stage, to minimize costs and fulfill a coordinating role taking into account the ever-increasing number of climate refugees, a UN organization which will perform coordination functions should be created [5].

\section{Conclusion}

An analysis of issue allowed us to conclude that the first direction seems the most optimal. The extension of the UN Convention on the Legal Status of Refugees and its 1967 protocol to environmental migrants seems to be the best for the international community for several reasons.

First of all, this is due to the similarity of the situation of asylum seekers in the territory of another state and people who left the place of their permanent residence due to natural disasters or technological accidents, environmental and climatic conditions.

\footnotetext{
* Corresponding author: 77712@live.ru
} 
In both cases, one can observe similar social processes that are the cause of forced migration from areas of permanent or temporary residence:

- an increase in social tension caused by social, political, class or religious motives or environmental disasters or a gradual deterioration of the environmental situation. There can be any cause of the increasing global social tension, including natural disasters, man-made accidents, deterioration of the environmental situation as a result of human industrial and environmental activities. In accordance with the definition of social tension as a stage preceding its development into a latent or open conflict, this social phenomenon “... represents the emotional state of a group or society as a whole, caused by pressure from the natural or social environment and continuing for a long time" [6].

In case of the negative impact of industrial activities on the environment, the basic contradiction of social tension is the unresolved discrepancy between needs and social expectations of society and a measure of their actual satisfaction. The situation that has developed around the death of the Aral Sea is the most striking example of this environmental and social conflict.

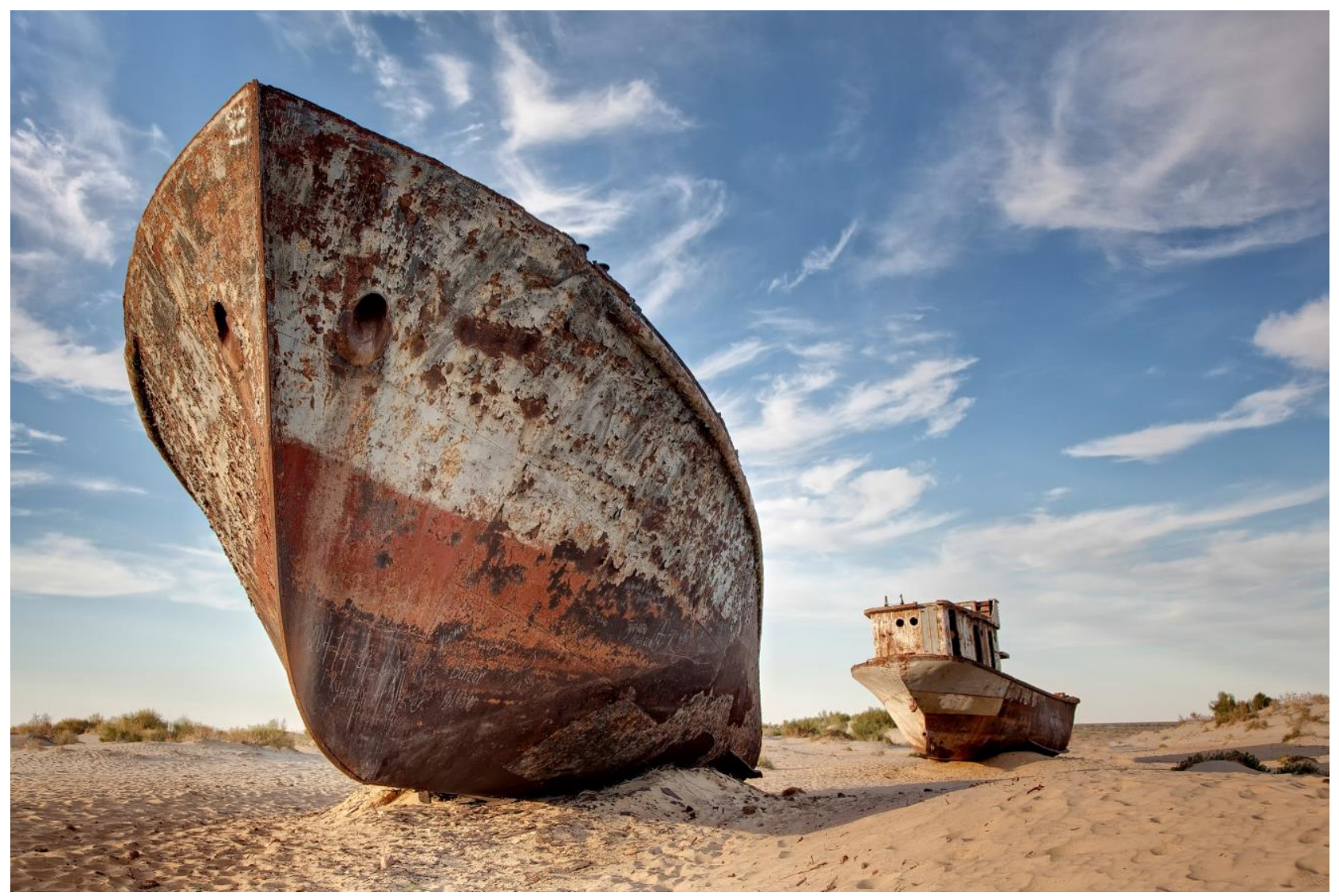

Fig. 2. Ecological disaster zone

Due to irrational reclamation activities, hundreds of square kilometers previously occupied by the Aral Sea turned into a desert suffering from salinization of soils. Two remaining small lakes have turned into the Dead Sea due to excessive salinity. This situation caused significant climate changes, an increased in the number of people suffering from tuberculosis, typhoid, hepatitis, psychosomatic diseases, etc.

- enhancing suspicion, mistrust, distrust of the authorities, amplified in the case of suspicion of concealing the true information about actual environmental conditions. The authorities cause the suspicions. The facts of hiding reliable information were observed during many industrial accidents, including accidents at the pesticide plant in Bhopal in 1982, at the fourth power unit of Chernobyl nuclear power plant in 1986, at the Fukushima-1 nuclear power plant in 2011, etc.;
- dissatisfaction with the current situation and fear for life and health manifested as rallies, demonstrations, riots, open acts of disobedience, increasing confrontation with official authorities.

Therefore, it is often difficult for individuals applying for the refugee status to identify the main reason that prompted them to leave the place of their permanent residence [7]. Moreover, there are examples of granting a refugee status to environmental migrants. In 1992, several thousand people who left Mozambique and Zambia were granted a refugee status, despite the fact that the main reason for the migration was a terrible drought that hit the neighboring state which significantly intensified social and political tension [8].

The UNHCR did not refuse to provide assistance and protection for this category of forced migrants. The UN Secretary-General emphasized the need to provide assistance to UN organizations, the UNHCR, various 
categories of forced migrants that do not meet the criteria provided for by the $1951 \mathrm{UN}$ Convention.

The second factor in favor of this decision is the availability of a capable, qualified and widely ramified UNHCR apparatus which can work with environmental migrants and protect their rights and freedoms. When joining the new edition of the Convention on the Legal Status of Refugees, the authorities can be involved in these activities, and environmental migrants will be able to obtain an international and national legal status, help and protection of the host state.

The research was carried out as part of RFFR grant 18-01100243 A

\section{References:}

1. V. Evtushenko, Yu. Shpakovsky. Legal regulation of the exercise of citizens' right to a favorable environment violated by natural and man-made emergencies. 2. 152-157. (2018)

2. D. Ivanov, D. Bekyashev. Ecological migration of the population: International legal aspects: Scientific publication. 10. (2013)
3. L. Brown, P. Mcgrath, and B. Stokes. Worldwatch Paper. Twenty-two dimensions of the population problem, 5. (1976)

4. J. McAdam. Climate Change, Forced Migration, and International Law Hardcover. (2012)

5. E. Markova. Actual problems of Russian law. International legal protection of environmental migrants: realities and prospects 7. 209 - 217. (2018)

6. V. Zarubin. Measurement of social tension theory, methodology and research methodology: materials of the All-Russian scientific-practical conference. Methodological aspects of the diagnosis of social tension in society. 9, (2002).

7. V. Evtushenko, Ecological migration as an integral part of the human security system and ensuring environmental safety, LEX RUSSICA, 6. 158-169. (2016).

8. M. Julienne. Every year thousands of people flee from advancing deserts, depleting forests and manmade disasters such as Chernobyl and Bhopal. Retrieved from: http://www.cybersciences.com (2019) 